\title{
Factors Affecting the Production of Elsinochrome Phytotoxin by the Citrus Scab Pathogen, Elsinoë fawcettii
}

\author{
Li-Yuan Wang ${ }^{1}$, Huey-Jiunn Bau $^{2}$, Hui-Ling Liao ${ }^{3}$ and Kuang-Ren Chung ${ }^{*}, 3$ \\ ${ }^{I}$ Department of Plant Protection, Chiayi Experiment Station, Taiwan Agricultural Research Institute, 2 Min-Cheng \\ Road, Chiayi 60014, Taiwan \\ ${ }^{2}$ Department of Biotechnology, Transworld Institute Technology, Douliu, 640 Taiwan \\ ${ }^{3}$ Citrus Research and Education Center, Institute of Food and Agricultural Sciences (IFAS), University of Florida, 700 \\ Experiment Station Road., Lake Alfred, Florida 33850, USA
}

\begin{abstract}
Elsinochrome (ESC), light-activated, nonhost-selective phytotoxin, is produced by many members of the genus Elsinoë and required for full virulence of the fungus. It appears that approaches disrupting the ESC production will likely reduce disease severity caused by Elsinoë pathogens. In this study, the influence of nutritional and environmental factors on ESC biosynthesis by the citrus scab pathogen E. fawcettii was investigated. Light is critical for initiation of ESC biosynthesis. E. fawcettii produced the highest amounts of ESC when grown on potato dextrose agar (PDA) in the light compared to other synthetic media. The fungus synthesized ESC in the presence of high amounts $\left(60 \mathrm{~g} \mathrm{l}^{-1}\right)$ of sucrose, under limiting nitrogen conditions, or in ambient $\mathrm{pH}$; ammonium completely inhibited production of ESC. ESC production was reduced when $\mathrm{Ca}^{2+}, \mathrm{Co}^{2+}, \mathrm{Li}^{+}$, cysteine, glutathione, hydrogen peroxide, pyridoxine or $\alpha$-tocopherol was added to PDA; however, addition of $\mathrm{Cu}^{2+}, \mathrm{Fe}^{3+}, \mathrm{K}^{+}, \mathrm{Mg}^{2+}, \mathrm{Mn}^{2+}$ or $\mathrm{Na}^{+}$ions increased ESC production. Addition of antioxidants, such as ascorbate, chlorogenic acid, catechin, or gallic acid into PDA enhanced ESC production substantially. Our results highlight the complexity of regulation of ESC biosynthesis by E. fawcettii at the biochemical and physiological levels.
\end{abstract}

Keywords: Antioxidants, perylenequinone, pigments, secondary metabolites.

\section{INTRODUCTION}

Elsinoë fawcettii Bitancourt \& Jenkins (anamorph: Sphaceloma fawcettii Jenkins) attacks a wide variety of citrus species and cultivars, resulting in scab disease on leaves, twigs, and fruit [1]. The disease is widespread in many humid, citrus-cultivating areas of the world and decreases fruit values for the fresh-fruit market. The necrotic lesions caused by E. fawcettii appear as a slight blemish and often form erumpent scab pustules comprised of fungal hyphae and host tissue. Affected leaves may develop lesions with warty or protuberant pustules emerging from one side of the leaf and a correspondingly depressed area on the opposite site.

Many phytopathogenic Elsinoë species produce elsinochrome (ESC) phytotoxin in culture [2]. ESC consists of at least four different tautomers with a common perylenequinone backbone and exhibits distinct red or yellow pigments upon secretion into the medium [2]. ESC structurally resembles many perylenequinone phytotoxins of fungal origins, such as cercosporin, stemphyltoxin, hypomycin, hypocrellin and phleichrome [2-4]. ESC produced by Elsinoë fungi share many similarities to cercosporin produced by Cercospora fungi, in terms of biosynthetic pathway and regulation, production of reactive oxygen species, mode of toxicity, and pathogenic roles in diseases. As with cercosporin [4-7], we

\footnotetext{
*Address correspondence to this author at the Citrus Research and Educa-
tion Center, IFAS, University of Florida, 700 Experiment Station Road.,

*Address correspondence to this author at the Citrus Research and Educa-
tion Center, IFAS, University of Florida, 700 Experiment Station Road., Lake Alfred, FL 33850. USA; Tel: 1 + (863) 956-1151, Ext. 1369; Fax: $1+$ (863) 956-4631; E-mail: krchung@ufl.edu
}

have previously shown that the toxicity of ESC is due primarily to the production of toxic reactive oxygen species, such as singlet oxygen and superoxide [8]. In addition, exposure of citrus leaves to ESC in the light resulted in severe electrolyte leakage, likely caused by membrane peroxidation [8]. Targeted disruption of a fungal polyketide synthase gene in E. fawcettii yielded mutants that failed to produce detectable ESC and with a drastically reduced ability to develop lesion on citrus [9], indicating that ESC is required for full virulence by $E$. fawcettii on citrus.

Studies of both cercosporin and ESC clearly indicate that the light-activated perylenequinone toxins produced by a number of phytopathogenic fungi play a crucial role in pathogenesis [10-12]. Production of cercosporin has been shown to be affected by complex nutrient conditions, $\mathrm{C} / \mathrm{N}$ ratios, ions, temperature and light and is highly variable among species, strains, even among isolates of a given species $[13,14]$. However, little research on ESC regulation responding to environmental conditions has been done. The aim of this study was to investigate environmental and nutritional factors influencing ESC production. The results revealed a complex, interconnected regulatory network leading to ESC accumulation, implicating that developing strategies to interfere with the toxicity of ESC will be useful in reduction of disease incidence caused by $E$. fawcettii.

\section{MATERIALS AND METHODOLOGY}

\section{Fungal Strains, Maintenance, and Culture Conditions}

The Elsinoë fawcettii Bitancourt \& Jenkins (anamorph: Sphaceloma fawcettii Jenkins) (Ascomycota, Elsinoaceae) iso- 
late CAL WH-1 used in this study has been previously characterized [9]. The fungus was grown on sterilize filter paper and maintained at $-20{ }^{\circ} \mathrm{C}$ for long-term storage. The basal media used for fungal growth and toxin production included: potato dextrose agar (PDA, Difco, Becton, Dickinson and Company, Sparks, MD, USA); a complete medium (CM) containing $1 \mathrm{~g}$ $\mathrm{Ca}\left(\mathrm{NO}_{3}\right)_{2} \cdot 4 \mathrm{H}_{2} \mathrm{O}, 0.2 \mathrm{~g} \mathrm{KH}_{2} \mathrm{PO}_{4}, 0.25 \mathrm{~g} \mathrm{MgSO}_{4} \cdot 7 \mathrm{H}_{2} \mathrm{O}, 0.15 \mathrm{~g}$ $\mathrm{NaCl}, 10 \mathrm{~g}$ glucose, $1 \mathrm{~g}$ each of yeast extract and casein hydrolysate and $15 \mathrm{~g} \mathrm{agar}^{-1}$ [13]; and a minimal medium (MM) containing all components of $\mathrm{CM}$, except yeast extract and casein hydrolysate. The $\mathrm{pH}$ of media was adjusted by $0.1 \mathrm{M}$ citric acid and $0.2 \mathrm{M}$ dibasic sodium phosphate as described [14]. Glucose or sodium nitrate in MM medium was substituted with equal molar concentration of other appropriate carbon or nitrogen sources.

To prepare fungal inoculum, the 5-day-old mycelium cultured on PDA under continuous fluorescent light (General Electric, $60 \mathrm{~W})$ at an intensity of 3.5 microeinstein $(\mu \mathrm{E}) \mathrm{m}^{-2}$ $\mathrm{s}^{-1}$ was ground with a sterile blender and suspended in sterile water. Hyphal suspension $(3 \mu \mathrm{l})$ was placed on the surface of the test medium $(5 \mathrm{ml})$ in a $60 \mathrm{~mm}$ diameter Petri dish and the plates were incubated in the light at $25{ }^{\circ} \mathrm{C}$. The plates were wrapped with aluminum foil for the dark control and incubated under the same conditions. Fungal growth was determined by measuring colony diameter after 3 weeks of incubation prior to ESC extraction.

\section{ESC Quantification}

For ESC quantification, four 6-mm diameter agar plugs cut from mycelial cultures were extracted with $5 \mathrm{M} \mathrm{KOH}$ in the dark for $16 \mathrm{~h}$, and absorbance of the extracts was measured at $480 \mathrm{~nm}$ by a model Genesys 5 spectrophotometer (Spectromic Instruments, Rochester, NY, USA). The ESC concentration was calculated using a molar extinction coefficient of $233001 \mathrm{~mol}^{-1} \mathrm{~cm}^{-1}$ [15] and was reported as nanomoles per agar plug. Data are the means of two or three different experiments each with at least three replicates. The significance of treatments was determined by analysis of variance, and treatment means were separated by the WallerDuncan's multiple range tests $(\mathrm{p}<0.05)$.

\section{Preparation of Chemicals}

Compounds, $\quad \mathrm{CaCl}_{2} \cdot 2 \mathrm{H}_{2} \mathrm{O}, \quad \mathrm{Ca}\left(\mathrm{NO}_{3}\right)_{2} \cdot 4 \mathrm{H}_{2} \mathrm{O}, \quad \mathrm{LiCl}$, $\mathrm{MgCl}_{2} \cdot 6 \mathrm{H}_{2} \mathrm{O}, \mathrm{NaCl}$ and $\mathrm{KCl}$, were purchased from Fisher Scientific (Suwanee, GA, USA), while all other chemicals used in this study were purchased from Sigma (St. Louis, MO, USA). Unless otherwise specified, all chemicals were dissolved in water to make a stock solution as appropriate. All aqueous solutions were sterilized by filtration. Bixin (carotenoid carboxylic acid), $\alpha$-tocopherol (vitamin E), and butylated hydroxyanisole (BHA) were dissolved in 95\% ethanol to make a stock solution. All the chemicals stock solutions were added to solid media to achieve appropriate concentrations. Equal volumes of sterile water or solvent were added to control treatments.

\section{RESULTS}

Fungal Growth and ESC Production in Response to Light, Medium Components and $\mathbf{p H}$

As assessed on PDA, E. fawcettii produced high amounts of ESC under constant light (Fig. 1A). The amounts of ESC accumulated sharply decreased when E. fawcettii was grown under a 12-h light /12-h dark cycle. ESC production was nearly abolished when the fungus was grown in continuous darkness. E. fawcettii grew slightly faster in light compared to other treatments. In constant light, production of ESC by the $E$. fawcettii isolate was highest when the fungus was grown on PDA and significantly reduced when grown on CM or MM (Fig. 1B). Fungal growth was also affected by the type of medium. Minimum medium (MM) contains the same ingredients as in the CM, except yeast extract and casein hydrolysate. Both media supported fungal radial growth equally. The fungus produced less ESC on CM than on MM, indicating that yeast extract or casein hydrolysate, or both inhibit or do not support maximal ESC production.

In addition, the effects on $\mathrm{pH}$ for fungal growth and ESC production were tested. A trend indicating a close correlation between ESC production and $\mathrm{pH}$ was observed, in which accumulation of ESC increased as the $\mathrm{pH}$ of medium was elevated (Fig. 1C). Thus, E. fawcettii produced ESC most abundantly under alkaline conditions. In contrast, fungal radial growth was slightly favorable at acidic $\mathrm{pH}$.

\section{ESC Production in Response to Nutrients}

To determine if ESC production is affected by nitrogen sources, calcium nitrate in MM was replaced with ammonium chloride or ammonium nitrate in varying concentrations as the sole nitrogen source and ESC production was measured. Both ammonium chloride and ammonium nitrate suppressed ESC production but only slightly affected fungal radial growth (Fig. 2A). At higher concentrations $>2 \mathrm{~g} \mathrm{l}^{-1}$ of ammonium chloride and ammonium nitrate, production of ESC was inhibited completely. On MM, production of ESC by $E$. fawcettii was enhanced when glucose was the sole carbon source, in a concentration-dependent manner (Fig. 2B). Substitution of glucose with sucrose significantly enhanced ESC production, whereas replacement of glucose with mannitol (at $60 \mathrm{~g}^{-1}$ ) resulted in a slight inhibitory effect on ESC production.

\section{Effects of Ions on ESC Production}

Addition of $\mathrm{CaCl}_{2}, \mathrm{Ca}\left(\mathrm{NO}_{3}\right)_{2} \cdot 4 \mathrm{H}_{2} \mathrm{O}, \mathrm{CoCl}_{2}$ or $\mathrm{LiCl}$ to PDA or MM decreased ESC production to various degrees (Fig. 3 and data not shown). Metal ions $\mathrm{Co}^{2+}$ at $1 \mathrm{mM}$ and $\mathrm{Li}^{2+}$ at 10-100 mM slightly suppressed fungal radial growth. Addition of $\mathrm{CuCl}_{2}, \mathrm{FeCl}_{3}, \mathrm{KCl}, \mathrm{MgCl}_{2}, \mathrm{MnCl}_{2}, \mathrm{NaCl}$ or $\mathrm{ZnCl}_{2}$, however, elevated ESC production to various levels, depending on the concentration of the compound tested (Table 1 and data not shown).

\section{Production of ESC is Affected by Antioxidants}

Since ESC generates reactive oxygen species in aerobic conditions upon exposure to light [4], experiments were performed to test if antioxidants, such as ascorbate, cysteine, 1,4-diazabicyclo-2,2,2-octante (DABCO), bixin and reduced glutathione, will influence ESC production and fungal growth. On MM, addition of DABCO, bixin (at $5 \mathrm{mM}$ ), butylated hydroxyanisole (BHA at $1 \mathrm{mM}$ ) or ascorbate (at 10 $\mathrm{mM}$ ) slightly elevated ESC production (Fig. 4A). BHA at 5 $\mathrm{mM}$ inhibited ESC production. In contrast, addition of ascorbate at $50 \mathrm{mM}$ to $\mathrm{MM}$ promoted ESC production substantially (Fig. 4A), yet only slightly enhanced fungal growth 
$\mathbf{A}$

B
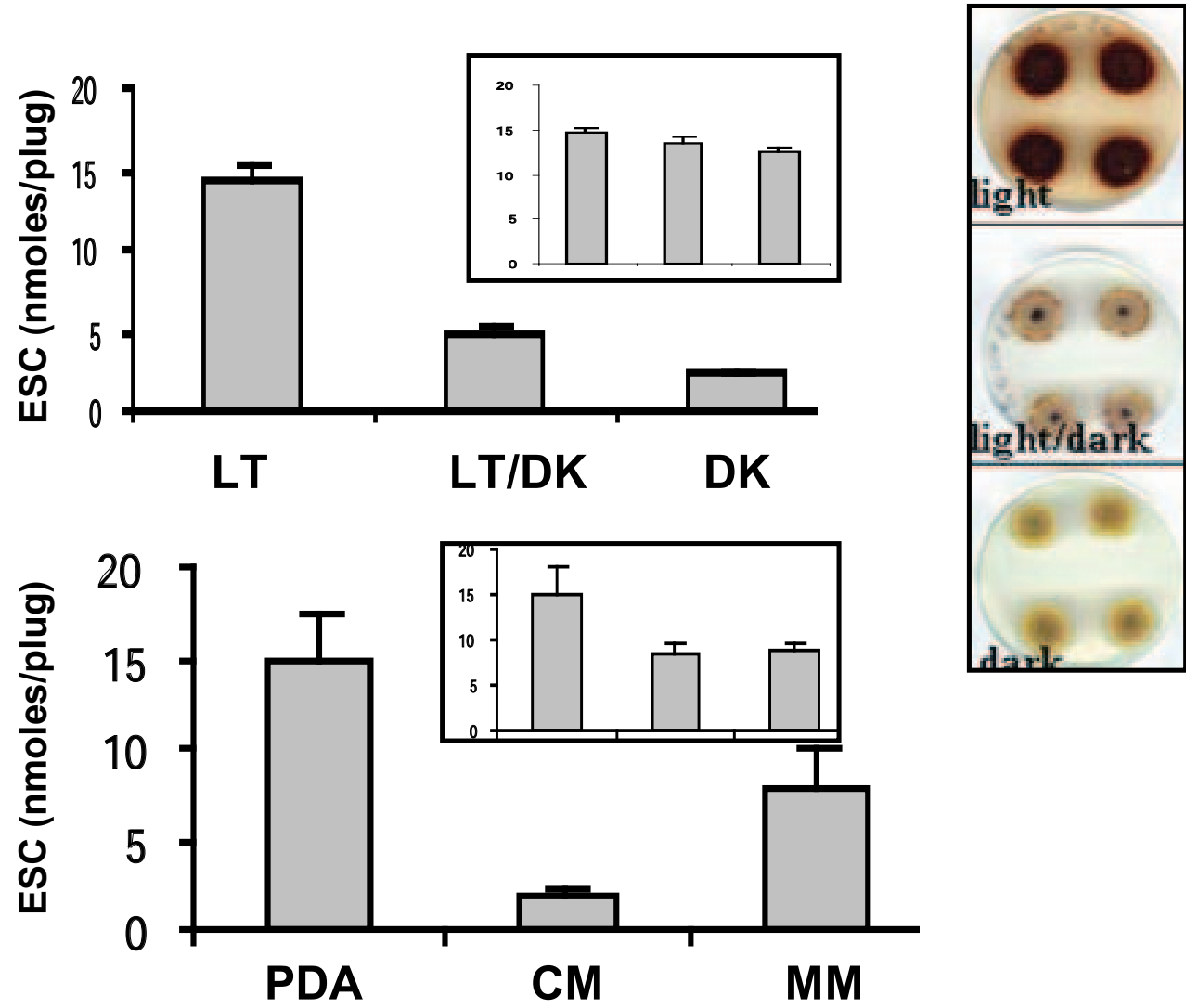

C

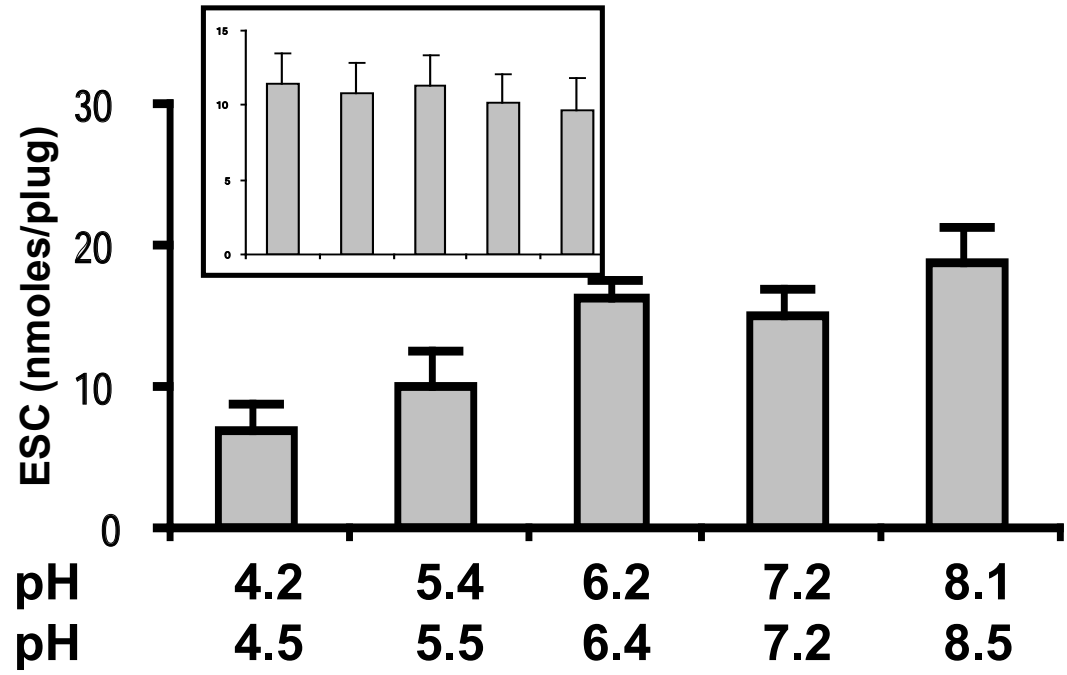

Fig. (1). Production of elsinochrome (ESC) phytotoxin by an isolate of the citrus scab pathogen, Elsinoë fawcettii in constant light (LT), in 12-h light/12-h dark cycle (LT/DK), or in darkness (DK) (A); on potato dextrose agar (PDA), complete medium (CM), or minimal medium (MM) (B); on PDA buffered at $\mathrm{pH}$ values with phosphate/citrate buffers as indicated (C). Insets indicate fungal radial growth (mm) from different treatments. Fungal cultures were incubated at $25{ }^{\circ} \mathrm{C}$ for 15 days in light or darkness and ESC was extracted with $5 \mathrm{M} \mathrm{KOH}$ and measured by absorbance at $480 \mathrm{~nm}$. Data shown are the means and the standard errors of two experiments, with three replicates of each treatment. Characterization of the light effect on ESC production is shown in the panel A. Dark pigments indicate the presence of ESC.

(data not shown). Co-application of ascorbate (at $10 \mathrm{mM}$ ) and $\mathrm{CuCl}_{2}$ or $\mathrm{FeCl}_{3}$ had no stimulatory effects for both ESC production and fungal growth (Fig. 4A and data not shown). Addition of $\mathrm{H}_{2} \mathrm{O}_{2}$ at $0.025 \%$ did not affect fungal radial growth but resulted in minor reduction of ESC accumulation; application of vanillic acid or caffeic acid (at $5 \mathrm{mM}$ ) had no effect on ESC production (Fig. 4A and data not shown). Fur- thermore, addition of chlorogenic acid, catechin or gallic acid did not affect fungal radial growth but substantially increased ESC production (Fig. 4B). Application of pyridoxine (vitamin B6 at $10 \mathrm{mM}$ ), cysteine (at $50 \mathrm{mM}$ ), $\alpha$-tocopherol (vitamin $\mathrm{E}$ at $20 \mathrm{mM}$ ), or reduced glutathione (at $10 \mathrm{mM}$ ) did not affect fungal growth and only slightly decreased ESC accumulation (Fig. 4B). 

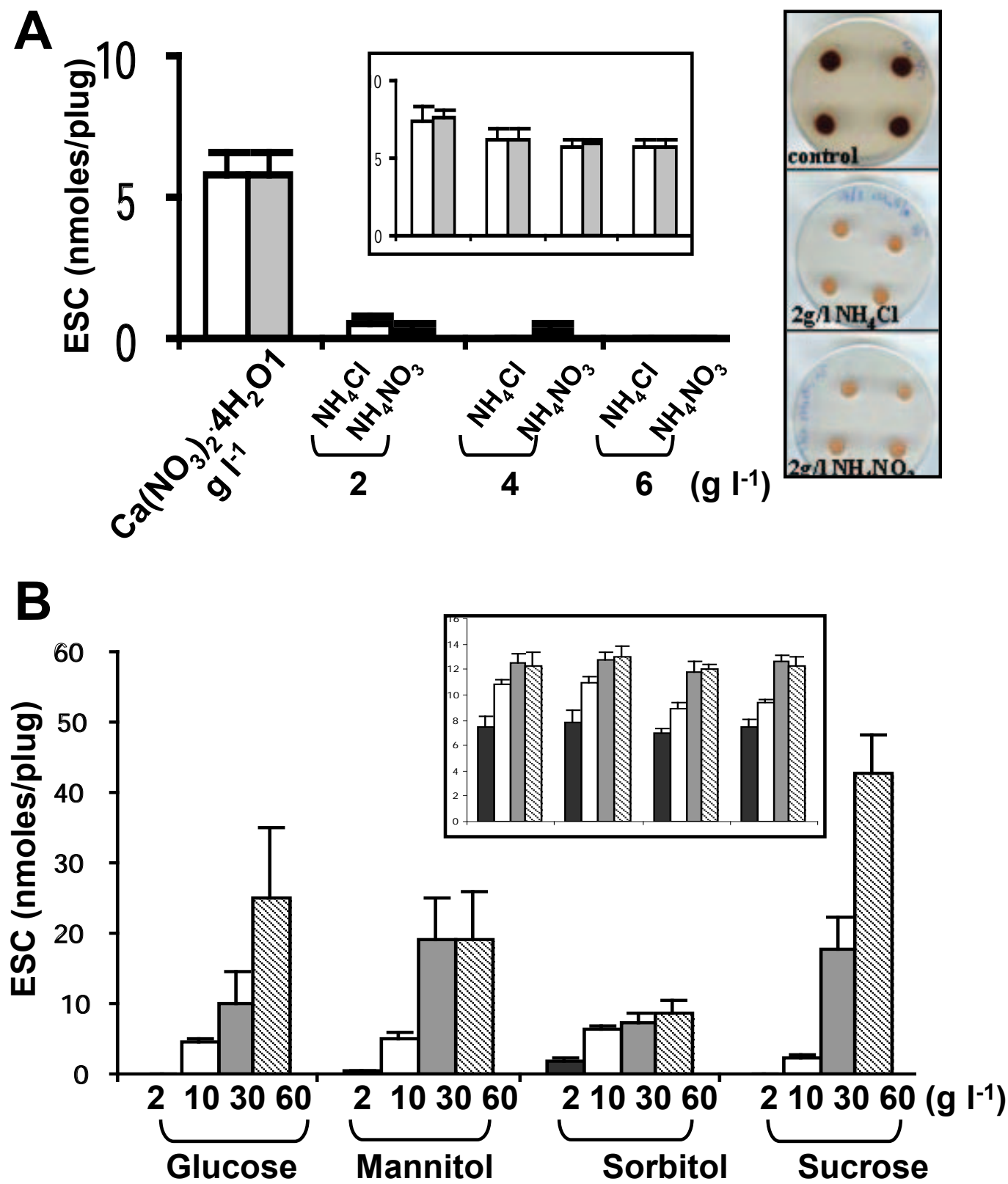

Fig. (2). Production of elsinochrome (ESC) phytotoxin by Elsinoë fawcettii grown on minimal medium (pH 5.3, adjusted by $0.2 \mathrm{M}$ sodium phosphate and $0.1 \mathrm{M}$ citrate buffer), replaced with various amounts of ammonium (A) or carbon sources (B) as indicated. Insets indicate fungal radial growth $(\mathrm{mm})$ in different treatments. Fungal cultures were incubated at $25{ }^{\circ} \mathrm{C}$ for 15 days under constant light and ESC was extracted with $5 \mathrm{M} \mathrm{KOH}$ and measured at $480 \mathrm{~nm}$. Data shown are the means and the standard errors of two experiments, with three replicates of each treatment. Characterization of the ammonium effect on ESC production is shown in panel A. Dark pigments indicate the presence of ESC.

\section{DISCUSSION}

Production and accumulation of secondary metabolites by microbes are often influenced by a number of environmental and nutritional factors. Physical parameters that affect production of secondary metabolites include light, temperature, and $\mathrm{pH}$. Nutritional factors such as carbon source and nitrogen source also affect production of secondary metabolites. Although significant progress has been made in identifying the environmental factors for production of fungal secondary metabolites, little is known about regulation of elsinochrome formation in E. fawcettii.
Many phytopathogenic Elsinoë spp. produce lightactivated, nonhost-selective phytotoxin called elsinochrome (ESC) whose structures resemble perylenequinone pigments, such as altertoxin I produced by Alternaria alternata, cercosporin produced by numerous Cercospora spp., hypocrellin A produced by Hypocrella bambusae, and phleichrome produced by Cladosporium spp. [3, 4]. Elsinochrome has been previously shown to be essential for fungal pathogenesis [9]. The production of ESC under laboratory conditions is growth-phase dependent and highly regulated by a variety of environmental and physiological factors, as demonstrated in this study. 


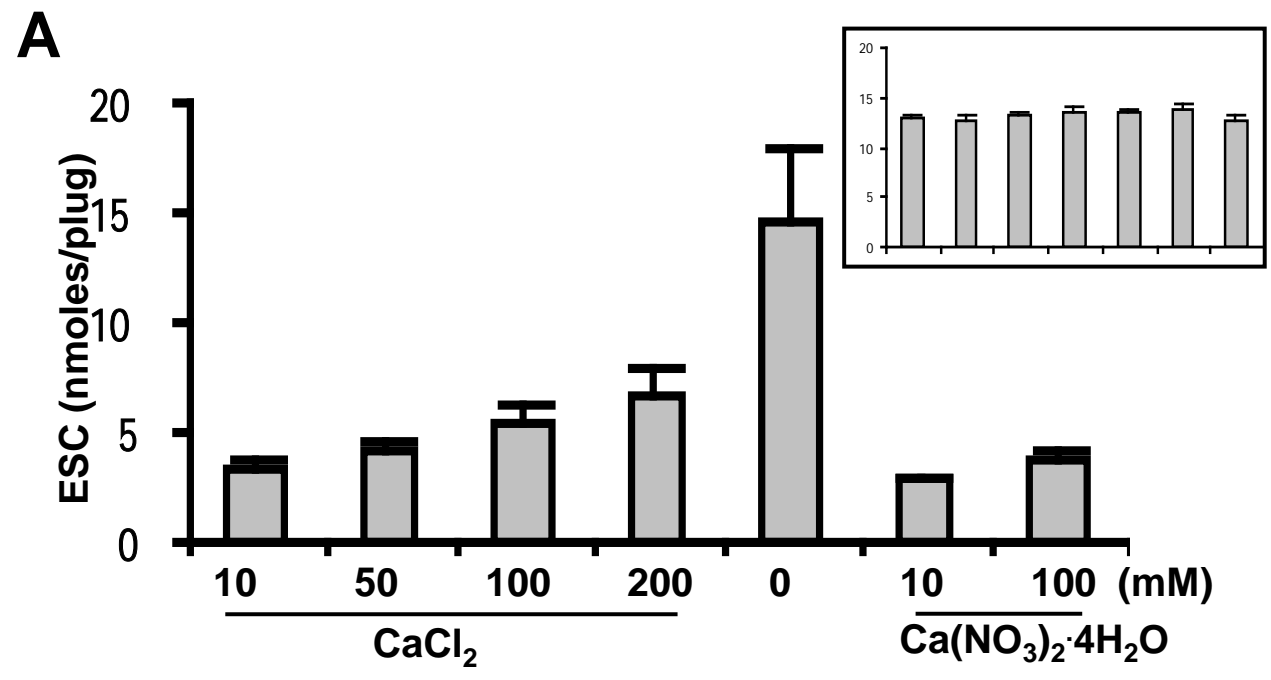

B

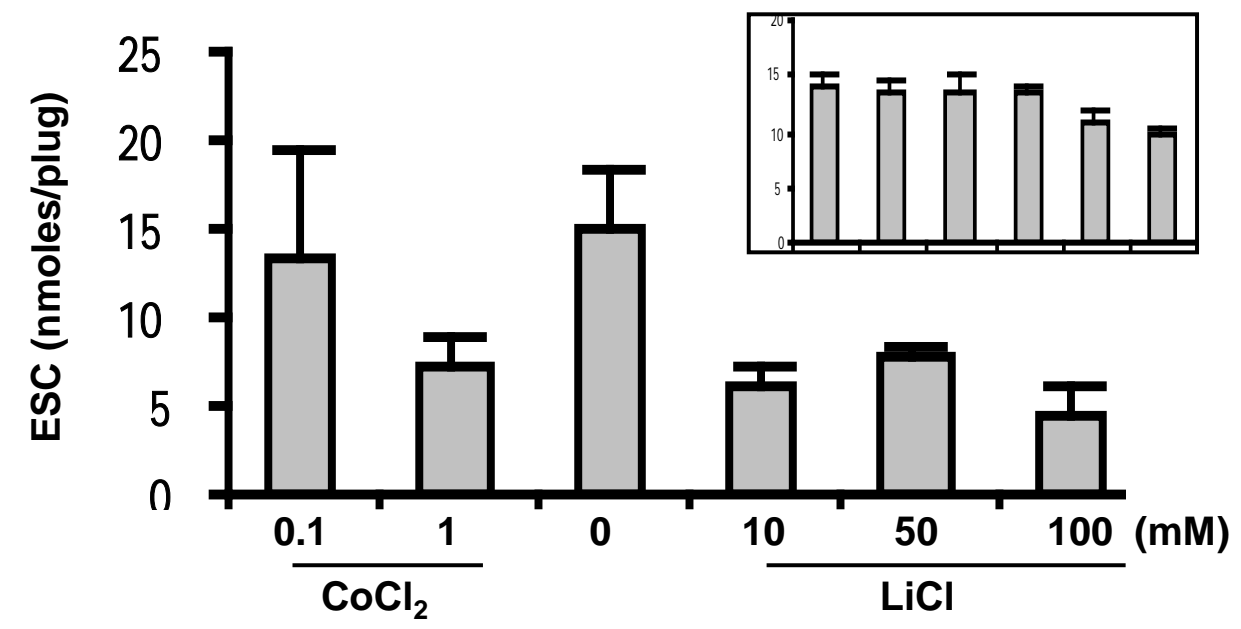

Fig. (3). Inhibition of elsinochrome (ESC) biosynthesis by Elsinoë fawcettii grown on PDA (pH 5.6) supplemented with various amounts of calcium chloride, calcium nitrate (A), or cobalt chloride, lithium chloride (B). Fungal cultures were incubated at $25{ }^{\circ} \mathrm{C}$ for 15 days under constant light and ESC was extracted with $5 \mathrm{M} \mathrm{KOH}$ and measured at $480 \mathrm{~nm}$. Data shown are the means and the standard errors of three experiments, with three replicates of each treatment. Dark pigments indicate the presence of ESC. Insets indicate fungal radial growth (mm) in different treatments.

Like the synthesis of cercosporin $[3,13,16]$, light has been demonstrated to be required for ESC biosynthesis and toxicity $[8,9]$. Elsinochrome was primarily produced when the fungus was incubated in light and its production was markedly suppressed in continuous darkness or in a light/dark cycle. We previously observed that light specifically triggers expression of the genes whose products are directly involved in the biosynthesis and regulation of ESC $[9,17]$. In addition to light, accumulation of ESC appears to be influenced by ambient $\mathrm{pH}$, nutrient medium, and carbon and nitrogen sources. We observed that E. fawcettii produces large quantities of ESC when grown at alkaline conditions. The ambient $\mathrm{pH}$ has been reported to serve as a regulatory cue for production of many fungal secondary metabolites, such as aflatoxin, sterigmatocystin, fumonsin, and penicillin [18-22]. In contrast, $\mathrm{pH}$ has little effect on the production of cercosporin toxin by Cercospora nicotianae [16]. Similar to cercosporin production, reduction of ESC production was not due mainly to the reduction of fungal growth since growth was not altered or was even promoted by many of the compounds.

Carbon sources generally have diverse effects on fungal development and production of secondary metabolites. Production of aflatoxin by Aspergillus spp. was greatly enhanced when fungi were cultured in a glucose-containing medium, but not in a mannitol-containing medium [21]. However, we found that $E$. fawcettii can also utilize glucose or mannitol for ESC production. Given that ESC is synthesized by a polyketide pathway, likely by condensation of acetyl-CoA and malonyl-CoA [9], one would expect that high concentration of carbon sources enhance the acetylCoA pool via glycolytic pathway and thus, boost ESC biosynthesis. Similarly, nitrogen sources have diverse effects in regulation of secondary metabolites in fungi. For example, sterigmatocystin and aflatoxin were produced in ammoniumbased media [21, 22], whereas production of alternariol 
Table 1. Production of Elsinochrome (ESC) by Elsinö fawcettii Grown on Potato Dextrose Agar (PDA) Supplemented with Inorganic Salts

\begin{tabular}{|c|c|c|c|}
\hline Treatment & Conc. $(\mathbf{m M})$ & Mean Colony Diameter $(\mathrm{mm}) \pm \mathrm{SEM}$ & ESC (nmoles per plug), Mean \pm SEM \\
\hline None & - & $13.5 \pm 0.4$ & $14.9 \pm 3.3$ \\
\hline \multirow{2}{*}{$\mathrm{CuCl}_{2} \cdot 2 \mathrm{H}_{2} \mathrm{O}$} & 0.1 & $14.0 \pm 0.3$ & $25.12 \pm 5.80$ \\
\hline & 1.0 & $13.5 \pm 0.9$ & $27.18 \pm 2.18$ \\
\hline \multirow{2}{*}{$\mathrm{FeCl}_{3}$} & 1.0 & $16.0 \pm 0.8$ & $26.0 \pm 1.8$ \\
\hline & 2.0 & $14.3 \pm 0.5$ & $34.8 \pm 2.7$ \\
\hline \multirow{2}{*}{$\mathrm{KCl}$} & 50.0 & $12.5 \pm 0.8$ & $32.8 \pm 5.2$ \\
\hline & 100.0 & $11.9 \pm 0.5$ & $24.5 \pm 7.6$ \\
\hline \multirow{2}{*}{$\mathrm{MgCl}_{2} \cdot 6 \mathrm{H}_{2} \mathrm{O}$} & 50.0 & $13.1 \pm 0.5$ & $36.5 \pm 7.5$ \\
\hline & 100.0 & $12.3 \pm 0.3$ & $45.7 \pm 6.2$ \\
\hline \multirow{2}{*}{$\mathrm{MnCl}_{2} \cdot 4 \mathrm{H}_{2} \mathrm{O}$} & 5.0 & $12.2 \pm 0.6$ & $24.9 \pm 3.2$ \\
\hline & 10.0 & $5.1 \pm 0.3$ & $20.5 \pm 4.5$ \\
\hline \multirow{2}{*}{$\mathrm{NaCl}$} & 50.0 & 12.6. \pm 0.5 & $15.2 \pm 6.9$ \\
\hline & 100.0 & $12.4 \pm 0.2$ & $30.4 \pm 5.4$ \\
\hline \multirow{2}{*}{$\mathrm{ZnCl}_{2}$} & 0.1 & $13.5 \pm 0.4$ & $19.9 \pm 6.9$ \\
\hline & 1.0 & $13.8 \pm 0.6$ & $19.6 \pm 3.6$ \\
\hline
\end{tabular}

The isolate of Elsinoë fawcettii was grown on potato dextrose agar (pH 5.6) supplemented with or without metal ions indicated, and incubated for 15 days in the light. Elsinochrome (ESC) was extracted twice with $5 \mathrm{M} \mathrm{KOH}$ and quantified by absorbance at $\mathrm{A}_{480}$. The data are shown as the mean of at least three different experiments, three replicates of each treatment \pm the standard error of the mean (SEM).

$(\mathrm{AOH})$ and alternariol monomethyl ether (AME) by Alternaria alternata were inhibited by sodium nitrate, glutamate or urea [23]. Furthermore, accumulation of cercosporin toxin, a perylenequinone produced by Cercospora fungi, was also suppressed by ammonium [16]. In Aspergillus spp., production of fungal secondary metabolites was controlled by complex regulatory networks involved in the G-protein/cAMP/protein kinase signaling cascades [21] in response to environmental cues. The present study points to the possibility that E. fawcettii might utilize similar signaling regulation for elsinochrome biosynthesis.

In prior studies, we demonstrated that two genes are required for elsinochrome biosynthesis: the EfPKS1 gene encoding a fungal polyketide synthase and the TSF1 gene encoding a $\mathrm{Cys}_{6} \mathrm{Zn}_{2}$ transcriptional regulator and their expression is regulated by light, carbon/nitrogen sources, and $\mathrm{pH}$ $[9,17]$. In addition, several DNA binding elements that are recognized and bound by global transcription factors for specific gene expression, such as C/EBP (cAMP-inducible genes) [24], AreA (nitrogen or light regulatory genes) [25], WC1/WC2 (light regulatory genes) [26] and $\mathrm{PacC}(\mathrm{pH}$ responsive genes) [27], were found in the promoter regions of the EfPKS1 and TSF1 genes [9, 17], suggesting that environmental signals affected ESC production, likely via transcriptional activation of the ESC biosynthetic genes.

This study also shows that some antioxidants interfere with the biosynthesis of ESC. Ascorbate, which has been reported to reduce $\mathrm{O}_{2}$ to $\mathrm{H}_{2} \mathrm{O}_{2}$ or to scavenge $\mathrm{H}_{2} \mathrm{O}_{2}$ from hydroxyl radicals in planta [28], enhances ESC production. Chlorogenic acid, catechin and gallic acid markedly stimulate ESC biosynthesis, whereas other potent antioxidants suppress or have no effect on ESC accumulation. Thus, it seems unlikely that the effects of those compounds on ESC biosynthesis are due to their antioxidant properties. In Fusarium verticillioides and $F$. proliferatum, butylated hydroxyanisol (BHA) and prophy paraben (PP) have been shown to inhibit fungal growth and toxin production [29, 30]; ascorbate enhances aflatoxin biosynthesis by Aspergillus parasiticus [31], yet caffeine, flavonoids, gallic acid and phenolics repress its biosynthesis [32]. Further, phenolic antioxidants have also been shown to inhibit ochratoxin A production by Aspergillus spp. [33, 34]. The effects of antioxidants on ESC accumulation remain unknown at this point. Some compounds may markedly alter environmental and physiological conditions regulated for ESC biosynthesis; others may modulate signaling transduction networks leading to ESC biosynthesis. In addition, some compounds may have direct effect on the biosynthetic gene expression or enzyme activity of dedicated steps in the ESC biosynthetic pathway.

In this study, we observed that $\mathrm{Ca}^{2+}, \mathrm{Co}^{2+}$ and $\mathrm{Li}^{+}$ions suppress ESC biosynthesis; $\mathrm{Cu}^{2+}, \mathrm{Fe}^{3+}, \mathrm{K}^{+}, \mathrm{Mg}^{2+}, \mathrm{Mn}^{2+}, \mathrm{Na}^{+}$ and $\mathrm{Zn}^{2+}$ ions enhance ESC biosynthesis. Extrinsic ions such as $\mathrm{Zn}^{2+}, \mathrm{Fe}^{3+}, \mathrm{Co}^{2+}$ and $\mathrm{Mn}^{2+}$ are also known to affect cercosporin and other toxin production in fungi [16, 35-38]. For example, $\mathrm{Zn}^{2+}, \mathrm{Fe}^{2+}$ and $\mathrm{Cu}^{2+}$ affect production of aflatoxins by Aspergillus flavus and zearalenone by Fusarium graminearum $[35,36]$. Metal ions may influence accumulation of fungal toxins by controlling expression of the genes whose products are required for toxin biosynthesis.

\section{CONCLUSIONS}

Biosynthesis of secondary metabolites in fungi is often regulated by nitrogen, in which a high concentration of inor- 

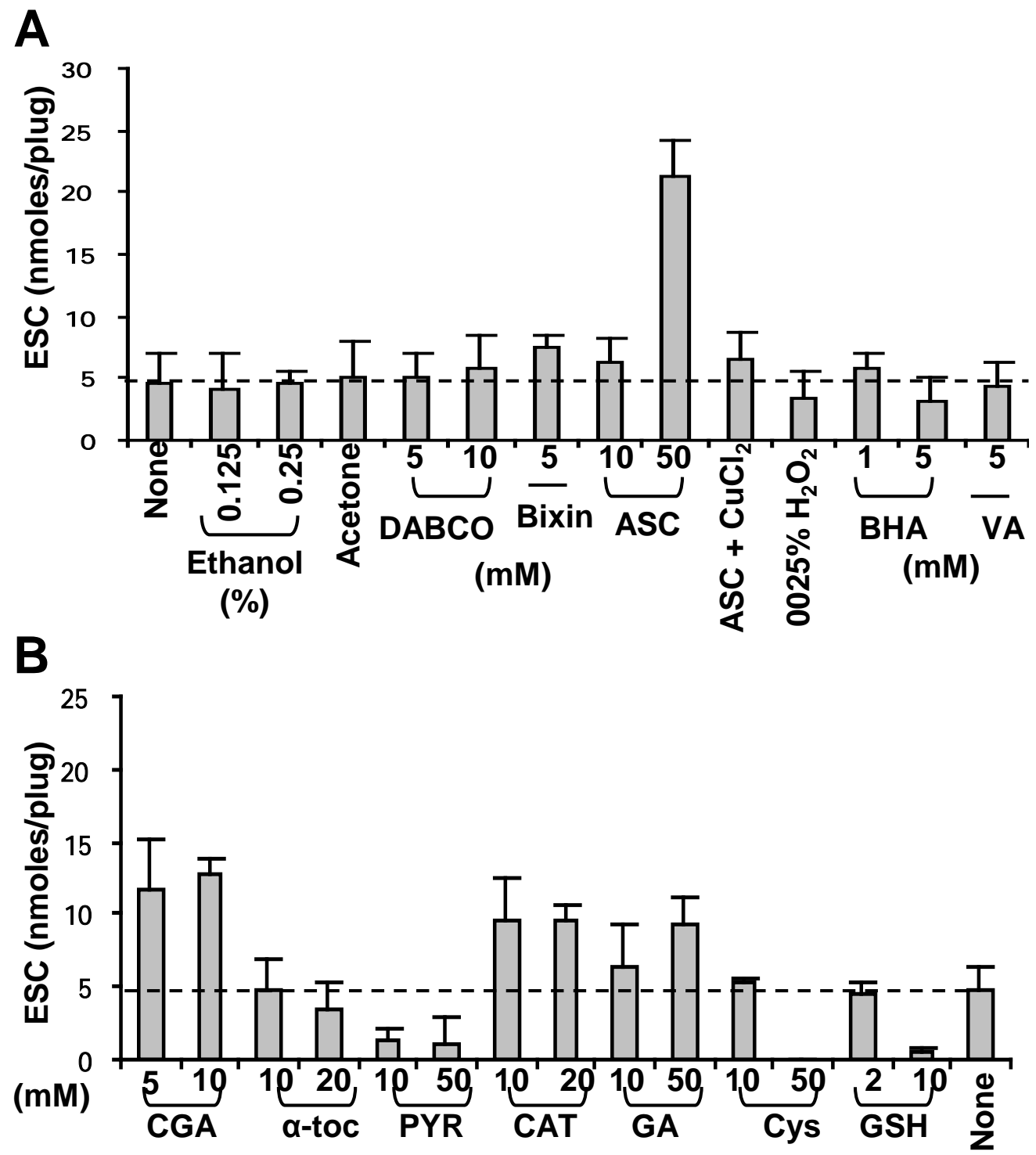

Fig. (4). (A, B) Production of elsinochrome (ESC) phytotoxin by Elsinoë fawcettii grown on minimal medium (pH 5.3) amended with different amounts of ethanol, acetone (controls), DABCO, bixin, ascorbic acid (ASC), hydrogen peroxide, butylated hydroxyanisole (BHA), vanillic acid (VA), chlorogenic acid (CGA), $\alpha$-tocopherol ( $\alpha$-toc), pyridoxine (PYR), catechin (CAT), gallic acid (GA), cysteine (Cys) or reduced glutathione (GSH). Fungal cultures were incubated at $25^{\circ} \mathrm{C}$ for 15 days under constant light and ESC was extracted with $5 \mathrm{M} \mathrm{KOH}$ and measured by absorbance at $480 \mathrm{~nm}$. The horizontal line indicates the quantity of ESC produced by E. fawcettii grown on minimal medium. None of the treatments significantly altered fungal radial growth (data not shown). Data shown are the means and the standard errors of two experiments, with five replicates of each treatment.

ganic nitrogen reduces the production of toxins and antibiotics. Elsinö̈ fawcettii produced large amounts of ESC when nitrogen was omitted from MM; however, the onset of ESC production was delayed and its accumulation was markedly reduced when MM or PDA was amended with excessive nitrogen. We also observed that expression of the ESC biosynthetic genes in E. fawcettii is nearly abolished in the presence of nitrogen source $[9,17]$. Taken together, we conclude that ESC production is negatively regulated by nitrogen and is apparently controlled by subtle and complex regulatory mechanisms.

\section{ACKNOWLEDGEMENT}

We thank H.-L. Liao for able assistance and gratefully acknowledge Dr. Daryl Henderson for initial editing. This research was supported by the Florida Agricultural Experiment Station and grants from the Florida Citrus Production Research Advisory Council.

\section{REFERENCES}

[1] Timmer LW, Pries M, Broadbent P, Tan MK. Morphological and pathological characterization of species of Elsinoë causing scab disease of citrus. Phytopathology 1996; 86: 1032-8.

[2] Weiss U, Merlini L, Nasini G. Naturally occurring perylenequinones. In: Herz W, Grisebach H, Kirby GW, Tamm C, Eds. Progress in the Chemistry of Organic Natural Products. New York, USA, Springer-Verlag Press 1987; pp. 2-71.

[3] Daub ME, Herrero S, Chung KR. Photoactivated perylenequinone toxins in fungal pathogenesis of plants. FEMS Microbiol Lett 2005; 252: $197-206$. 
[4] Daub ME, Ehrenshaft M. The photoactivated Cercospora toxin cercosporin: contributions to plant disease and fundamental biology. Annu Rev Phytopathol 2000; 38: 461-90.

[5] Daub ME. Cercosporin, a photosensitizing toxin from Cercospora species. Phytopathology 1982a; 72: 370-4.

[6] Daub ME. Peroxidation of tobacco membrane lipids by the photosensitizing toxin, cercosporin. Plant Physiol 1982b; 69: 1361-4.

[7] Daub ME, Hangarter R. Light-induced production of singlet oxygen and superoxide by the fungal toxin, cercosporin. Plant Physiol 1983; 73: 855-7.

[8] Liao HL, Chung KR. Cellular toxicity of elsinochrome phytotoxins produced by the pathogenic fungus, Elsinoë fawcettii causing citrus scab. New Phytologist 2008a; 177: 239-50.

[9] Liao HL, Chung KR. Genetic dissection defines the roles of elsinochrome phytotoxin for fungal pathogenesis and conidiation of the citrus pathogen Elsinoë fawcettii. Mol Plant-Microbe Interact 2008b; 21: 469-79.

[10] Chen HQ, Lee MH, Daub ME, Chung KR. Molecular analysis of the cercosporin biosynthetic gene cluster in Cercospora nicotianae. Mol Microbiol 2007; 64: 755-70.

[11] Choquer M, Dekkers KA, Ueng PP, Daub ME, Chung KR. The $C T B 1$ gene encoding a fungal polyketide synthase is required for cercosporin biosynthesis and fungal virulence of Cercospora nicotianae. Mol Plant-Microbe Interact 2005; 18: 468-76.

[12] Dekkers LA, You BJ, Gowda VS, et al. The Cercospora nicotianae gene encoding dual $O$-methyltransferase and FAD-dependent monooxygenase domains mediates cercosporin toxin biosynthesis. Fungal Genet Biol 2007; 44: 444-54.

[13] Jenns AE, Daub ME, Upchurch RG. Regulation of cercosporin accumulation in culture by medium and temperature manipulation. Phytopathology 1989; 79: 213-9.

[14] You BJ, Choquer M, Chung KR. The Colletotrichum acutatum gene encoding a putative $\mathrm{pH}$-responsive transcription regulator is a key virulence determinant during fungal pathogenesis on citrus. Mol Plant-Microbe Interact 2007; 20: 1149-60.

[15] Yamazaki S, Ogawa T. The chemistry and stereochemistry of cercosporin. Agric Biol Chem 1972; 36: 1707-18.

[16] You BJ, Lee MH, Chung KR. Production of cercosporin toxin by the phytopathogenic Cercospora fungi is affected by diverse environmental signals. Can J Microbiol 2008; 54: 259-69.

[17] Chung KR, Liao HL. Determination of a transcriptional regulatorlike gene involved in biosynthesis of elsinochrome phytotoxin by the citrus scab fungus, Elsinoë fawcettii. Microbiology 2008; 154: 3556-66.

[18] Cotty PJ. Aflatoxin and sclerotial production by Aspergillus flavus: influence of pH. Phytopathology 1988; 78: 1250-3.

[19] Shah AJ, Tilburn J, Adlard MW, Arst HN Jr. pH regulation of penicillin production in Aspergillus nidulans. FEMS Microbiol Lett 2006; 77: 209-12.

[20] Keller NP, Nesbitt C, Sarr B, Phillips TD, Burrow GB. pH Regulation of sterigmatocystin and aflatoxin biosynthesis in Aspergillus spp. Phytopathology 1997; 87: 643-8.

[21] Calvo AM, Wilson RA, Bok JW, Keller NP. Relationship between secondary metabolism and fungal development. Microbiol Mol Biol Rev 2002; 66: 447-59.
[22] Flaherty JE, Pirttilä AM, Bluhm BH, Woloshuk CP. PAC1, a pHregulatory gene from Fusarium verticillioides. Appl Environ Microbiol 2003; 69: 5222-7.

[23] Orvehed M, Häggblom P, Söderhäll K. Nitrogen inhibition of Mycotoxin production by Alternaria alternata. Appl Environ Microbiol 1988; 54: 2361-4.

[24] Rangan VS, Oskouian B, Smith S. Identification of an inverted ccaat box motif in the fatty-acid synthase gene as an essential element for mediation of transcriptional regulation by cAMP. J Biol Chem 1996; 271: 2307-12.

[25] Marzluf GA. Genetic regulation of nitrogen metabolism in the fungi. Microbiol. Mol Biol Rev 1997; 61: 17-32.

[26] Linden $\mathrm{H}$, Macino G. White collar-2, a partner in blue light signal transduction, controlling expression of light-regulated genes in Neurospora crassa. EMBO J 1999; 16: 98-107.

[27] Espeso EA, Tilburn J, SaÂnchez-Pulido L, Brown CV, Valencia A, Arst HN Jr. Peñalva MÁ, Specific DNA recognition by the Aspergillus nidulans three zinc finger transcription factor PacC. J Mol Biol 1997; 274: 466-80.

[28] Fry SC. Oxidative scission of plant cell wall polysaccharides by ascorbate-induced hydroxyl radicals. Biochem J 1998; 332: 507-15.

[29] Reynoso MM, Torres AT, Ramirez ML, Rodríguez MI, Chulze SN, Magan N. Efficacy of antioxidant mixtures on growth, fumonisin production and hydrolytic enzyme production by Fusarium verticillioides and $F$. proliferatum in vitro on maize-based media. Mycol Res 2002; 106: 1093-9.

[30] Farnochi MC, Torres AM, Magan N, Chulze SN. Effect of antioxidants and competing mycoflora on Fusarium verticillioides and $F$. proliferatum populations and fumonisin production on maize grain J Stored Prod Res 2005; 41: 211-9.

[31] Patel UD, Bapat SR, Dave PJ. Induction of aflatoxin biosynthesis in Aspergillus parasiticus by ascorbic acid-mediated lipid peroxidation. Curr Microbiol 1990; 20: 159-64.

[32] Holmes RA, Boston RS, Payne GA. Diverse inhibitors of aflatoxin biosynthesis. Appl Microbiol Biotechnol 2008; 78: 559-72.

[33] Palumbo JD, O'Keeffe TL, Mahoney NE. Inhibition of ochratoxin A production and growth of Aspergillus species by phenolic antioxidant compounds. Mycopathologia 2007; 164: 241-8.

[34] Passone MA, Resnik SL, Etcheverry MG. In vitro effect of phenolic antioxidants on germination, growth and aflatoxin $\mathrm{B}_{1}$ accumulation by peanut Aspergillus section Flavi. J Appl Microbiol 2005; 99: 682-91.

[35] Marsh P, Simpson ME, Truckess MW. Effects of trace metals on the production of aflatoxins by Aspergillus parasiticus. Appl Microbiol 1975; 30: 52-7.

[36] Cuero R, Smith JE, Lacey J. Mycotoxin formation by Aspergillus flavus, Fusarium graminearum in irradiated maize grains in the presence of other fungi. J Food Prot 1988; 50: 452-6.

[37] Jackson M, Slinger PJ, Bothast RJ. Effects of zinc, iron, cobalt, and manganese on Fusarium moniliforme NRRL 13616 growth and fusarin C. biosynthesis in submerged cultures. Appl Environ Microbiol 1989; 55: 649-55.

[38] Cuero R, Ouellet T. Metal ions modulate gene expression and accumulation of the mycotoxins aflatoxin and zearalenone. J Appl Microbiol 2005; 98: 598-605. 